\title{
Comparative Studies on the Physico-chemical Characteristics of Bio-materials with Collagen from Calf and Fish Skins from Black Sea
}

\author{
MELAT CHERIM ${ }^{1}$, RODICA SIRBU ${ }^{1}$, ANETA TOMESCU ${ }^{2 *}$, MARIUS FLORENTIN POPA ${ }^{2}$, EMIN CADAR ${ }^{1}$ \\ ${ }^{1}$ Ovidius University of Constanta, Faculty of Pharmacy, 24 Mamaia Blvd., 900527, Constanta, Romania \\ ${ }^{2}$ Ovidius University of Constanta, Faculty of Medicine, 24 Mamaia Blvd., 900527, Constanta, Romania
}

\begin{abstract}
Collagen hydrolysers are three-dimensional polymeric materials with limited cross-linking and high hydrophilicity, having multiple medical applications. The most used collagen is the one extracted from bovine skin, which is now the industrial source of collagen. Due to the outbreak of some threatening diseases such as BSE, transmissible spongiform encephalopathy, foot-and-mouth disease, researchers have sought a safer alternative to collagen. This was the marine resource, which offered multiple opportunities to capitalize on clean sea-water raw material. This paper presents a comparative study of the physicochemical properties of collagen hydrogels derived from collagen obtained from calf and skin from the Black Sea. Physico-chemical and spectrophotometric analyzes were performed to determine the structure. Studies have been conducted to analyze rheological behavior, antioxidant activity and antimicrobial activity. The total antioxidant capacity (ACL) is higher for collagen mixtures with $40 \%$ ethyl alcohol and shows higher values for fish collagen compared to calf collagen. Antimicrobial analysis shows that all collagen hydrogels show antimicrobial activity, both gram-positive (Staphylococcus aureus ATCC 6538P) and gram-negative (Escherichia coli ATCC 10536), which increases with increasing collagen concentrations.
\end{abstract}

Keywords: collagen hydrogels, calf collagen, fish collagen, actioxidant capacity, antimicrobian activity

Collagen in all its characteristic forms is presented as a polymer that is distinguished by increased hydrophilicity, variable ionic character and diverse functionality, and can be involved in a large number of interaction systems with other micro or macromolecular components [1]. To date, at least 29 different types of collagen have been identified, which are composed of 46 distinct polypeptide chains [ 23], differentiated by their structure into: striatum (fibrous), non-fibrous (network formation), microfibrillation (filamentous) and those that are associated with fibrils [4]. All have a triple helix characteristic, but the length and size of the helix and the nature of the non-helical portion vary from one type to another [5-6]. Triple helix molecules have terminal globular domains and are called procollagen. These globular regions are cleaved to different degrees to give a polymerized structure (tropocollagen), which is the base unit of collagen. The amino acid sequence in collagen is generally a repetitive tripeptide unit (Gly-X-Y), where $X$ is frequently Pro and $Y$ is Hyp [7-8]. Collagen possesses the characteristics of a distinct biomaterial in the biopolymer class [9-13]. Collagen has a broad utility as a biomaterial in the treatment of wounds [14-15]. The skin is permanently subjected to various lesions and is injured by physical or chemical means [16-17]. There have been researches in the last decades of numerous materials that could accelerate wound healing [18-20]. Collagenic hydrogels are polymeric materials with three-dimensional structure, limited cross-linking and high hydrophilicity that are applied topically. Due to these characteristics, hydrogels can absorb a high amount of water and give the wound a wet environment and at the same time have the ability to absorb the exudates produced by it [21]. Depending on the materials used, hydrogels may be natural, synthetic or semi-synthetic. [22-23]. Bovine source is one of the major industrial sources of collagen, used especially in the pharmaceutical and biomedical fields [24-28]. One of the major drawbacks of bovine collagen is that almost $3 \%$ of the population is allergic to it, which is a hindrance to its use. Due to the outbreak of menacing diseases such as $\mathrm{BSE}$, transmissible spongiform encephalopathy (FMD), foot-and-mouth disease (FMD), researchers have sought a safer collagen alternative. This was the marine resource, which offered multiple possibilities to harness clean raw material if it came from sea-fishing [29-31]. Although collagen extracted from fish does not form high viscosity gels, they are very convenient for certain applications, such as micro-encapsulation or obtaining light-sensitive coatings. From collagen gels, as in the case of those extracted from mammalian skin, porous films or matrices can be obtained. The present study includes original research on fish in the Black Sea. This paper is a comparative study on the physico-chemical characteristics of collagen hydrogels derived from collagen obtained from bovine skin and fish from the Black Sea. The study period was 2017-2018.

\section{Experimental part}

Materials and methods

Insoluble calf collagen fibers were obtained in the Collagen Department of the Romanian National Research $\&$ Development Institute for Textiles and Leather, from calf hide, through a special chemical enzymatic process [32]. Fish Collagen was obtained from Gray Mullet fish from the Black Sea through a bio-technological process of acid extraction [33]. Practically, two extraction variants were performed: Variant I with $0.5 \mathrm{M}$ acetic acid and variant II with $0.1 \mathrm{M}$ hydrochloric acid. The cross-linking agents used were tannic acid.

\section{Chemicals}

All used reagents were of analytical reagent grade and were purchased from Sigma-Aldrich, Germany. The tested microoganisms: Staphylococcus aureus (ATCC 65389P), Escherichia coli (ATCC 10536). 


\section{Collagen Biomaterials}

As a support in the production of biomaterials, collagen extracted and characterized from Gray Mullet skin of the Black Sea was used and collagen from calf skin. Biomaterials have been made with hydrogels, membranes (films) and matrices. The methods of obtaining biomaterials were as follows:

- collagenic hydrogels were obtained by mixing the adjusted gels at $0.4 \%$ and $\mathrm{pH} 7$ with triethanolamine and different active substances in different concentrations from the dry substance. The hydrogels were crosslinked with $10 \%$ tannic acid over collagen and maintained at $4{ }^{\circ} \mathrm{C}$ for $24 \mathrm{~h}$;

- the membranes (films) were obtained from the crosslinked hydrogels by pouring into Petri plates. Drying was carried out at room temperature, $22{ }^{\circ} \mathrm{C}$, for $24-72 \mathrm{~h}$;

- matrices were obtained from collagen lyophilisates. The hydrogels were lyophilized using the Lacombco lyophilizer and had the same composition as the collagen hydrolyzates.

\section{Investigation methods}

Physico-chemical characteristics were obtained from the following analyzes: total nitrogen, protein, $\mathrm{pH}$, dry matter content, ash content. Preliminary determination of appearance, color and determination of moisture were made. The analyzes were performed according to the Romanian Pharmacopoeia ed. X [34] and the European Pharmacopoeia [35]. The analyzed samples were harvested on collagen hydrolysates extracted from bovine skin and Gray Mulletskin obtained by acid treatment with $0.5 \mathrm{M}$ acetic acid and $0.1 \mathrm{M} \mathrm{HCl}$.

\section{Determination of collagen content}

By determining hydroxyproline, itis possible to determine the amount of collagen and thus determine its proportion of total proteins using a method described by Macovescu G. named the spectrophotometric determination of hydroxyproline following Ehrlich reagent therapy [36]. To determine the percentage content of hydroxiproline, a Hellios Omega Thermo Scientific series 171008 spectrometer, suitable for use at a wavelength of $558 \mathrm{~nm}$ $\pm 2 \mathrm{~nm}$. The percentage of collagen is calculated, based on the percentage of hydroxyproline, after the relationship (1) [37]:

$$
\text { Collagen content } \%=\mathrm{HPro} \text { content } \% * 8
$$

\section{Analysis by FTIR Spectroscopy}

Infrared spectroscopy is sensitive to the chemical structures of molecules and is suitable for spectroscopy to determine proteins and polypeptides in differentstates and concentrations and is a useful tool for determining the secondary structure of proteins and polypeptides [38]. FTIR analysis was performed with a FTIR 4200 Jasco Spectrometer.

\section{Analysis by UV-DC Spectroscopy}

Circular dichroism is an important method for analyzing the helical structure and the degree of renaturation / denaturation of samples used in biological studies. The UV-DC spectrums were obtained with a Jasco J-810 spectrophotometer, The spectrum represents the mediation of four consecutive acquisitions at room temperature $\left(25^{\circ} \mathrm{C}\right)$.

\section{Analysis of rheological behavior}

The rheological behavior under shear stresses was determined at $23 \pm 0.1^{\circ} \mathrm{C}$ with a Haake VT 550 reoviscometer equipped with the medium viscosity MV1 sensor system and Rheo-Win 4 Thermo Fischer Scientific software. Comparative rheology studies have been performed on both collagen extracted from calf skin and collagen extracted from fish skin. Both samples were nonreticulated and crosslinked with $2 \%$ tannic acid. (table 1 )

Rheological behavior is analyzed using equations (2) :(5) shown in table 2.

Dynamic rheological measurements were performed with the Micro Fourier Transform Rheometer MFR 2100 microcontroller (GBC model), a compressor flow micrometer equipped with a temperature control jacket connected to a Lauda E100 circulation water bath. By the Fourier analysis of the force signal, at a large number of discrete simultaneous frequencies, the main viscoelastic characteristics of the sample can be extracted: the storage G' and loss G' module, the complex viscosity and its components. All rheological measurements were performed in triplicate (with a standard deviation of less than $15 \%$ ) at $25^{\circ} \mathrm{C}$.

\section{Determination of total antioxidant activity by chemiluminescence ( $A C L$ )}

The important criteria for choosing the ACL method by photochemiluminescence includes the short time needed for the analysis and for the preparation of the sample. Components of the reagent kit for the ACL procedure: high purity R1 - methanol; - reagent R2 - reagent buffer; Reagent R3 - photosensitizer reagent and free radical detection reagent; - $\mathrm{R} 4$ reagent - the calibration standard (trolox), for quantification of lipid-soluble antioxidant substances [39]. The equipment used in the ACL method is produced by Analytik Jena AG, has made available a system that can measure the full antioxidant ( $A C L)$ capacity of a mixture of substances. The calibration curve for the standard substance trolox was built using a series of standard solutions trolox concentrations of $0.5,1.0,1.5$, 2.0 and $3.0 \mathrm{nmol} /$ sample volume. The measured

Table 1

COMPOSITION OF COLLAGEN HYDROGELS

\begin{tabular}{|l|l|}
\hline Sample 1 (COL-Calf) & $1.72 \%$ calf collagen in $0.5 \mathrm{M}$ acetic acid \\
\hline Sample 2 COL-Calf-R) & $1.72 \%$ calf collagen, $10 \%$ tannic acid in $0.5 \mathrm{M}$ acetic acid \\
\hline Sample 3 (COL-Fish) & $0.4 \%$ fish collagen in $0.5 \mathrm{M}$ acetic acid \\
\hline Sample 4 (COL-Fish-R) & $0.4 \%$ fish collagen, $0.04 \%$ tannic acid in $0.5 \mathrm{M}$ acetic acid \\
\hline
\end{tabular}

Table 2

EQUATIONS USED IN REOLOGICAL MEASUREMENTS OF STUDIED BIOCOMPOSITIONS

\begin{tabular}{|c|c|c|c|}
\hline $\begin{array}{c}\text { Viscosity } n(\mathrm{cP}) \text { depending } \\
\text { on shear speed } D\left(\mathrm{sec}^{-1}\right)\end{array}$ & $\begin{array}{c}\text { Shear speed } D\left(\mathrm{sec}^{-1}\right) \\
\text { depending on shear } \\
\text { stress } \tau(\mathrm{Pa})\end{array}$ & $\begin{array}{c}\text { Shear speed } \mathrm{D}\left(\mathrm{sec}^{-1}\right) \text { in } \\
\text { correlation with the selected } \\
\text { rotation speed } \omega(\mathrm{rpm})\end{array}$ & $\begin{array}{c}\text { shear stress } \tau \text { (Pa) depending } \\
\text { on viscosity } \eta(P) \text { and shear } \\
\text { speed } D\left(\mathrm{sec}^{-1}\right)\end{array}$ \\
\hline$\eta=\mathrm{f}(\mathrm{D})$ (2) & $\mathrm{D}=\mathrm{f}(\tau)$ (3) & $\mathrm{D}=\omega^{*} \mathrm{R} \quad(4)$ & $\tau=\eta^{*} \mathrm{D}$ \\
\hline
\end{tabular}


antioxidant capacity is then quantified by comparison with a standard substance used for calibration. (trolox - vitamin $\mathrm{E}$ derivative). The analyzed material is based on calf collagen hydrolyzate and Gray Mulletmarine fish in aqueous and alcoholic solutions of varying concentrations of ethyl alcohol.

\section{Determination of antimicrobial activity of biocomposites}

The diffusometric method of Bauer A.W. was used with some modifications [40] with wells cut from the nonspecific nutrient agar medium. The microorganisms used for antimicrobial activity evaluation are gram-positive bacteria Staphylococcus aureus (ATCC 6538P) and gramnegative bacteria Escherichia coli (ATCC 10536). For each of the strains we prepared a standard reference solution, an Inocculum, of known concentration $\left(3 \times 10^{-8} / \mathrm{mL}\right)$. We used Petri dishes in which we added $1 \mathrm{~mL}$ of reference solution (Inocculum) and $80 \mathrm{~mL}$ of nonspecific nutrient agar, sterilized and homogenized. In parallel, we also prepared 3 positive control plates to compare the results obtained. After solidifying the agar from the Petri plates we made the wells, aseptically, using a sterilized matrix of known diameter. Non-specific nutritional agar plates were filled with the known bacterial medium and we measured the inhibition halos formed by collagen hydrogels. Inhibition halos result from the activity of collagen hydrolysates on culture media by preventing the development of pathogens and their proliferation in the agar medium.

\section{Statistical analysis}

A statistical approach was designed and the experimental data were evaluated using one-way analysis of variance (ANOVA). The statistical results confirm the hypothesis that the differences between the results are either not significant $(p>0.05)$. The average of multiple measurements (triplicates or more) was listed in the tables together with the standard deviations.

\section{Results and discussions}

Among natural polymers, bovine collagen has been used in multiple applications. The results of the present study show the physico-chemical characteristics of collagen hydrogels from calf and Gray Mullet skin from the Black Sea. The marine collagen hydrogels were obtained by two different acid extraction processes: $0.5 \mathrm{M}$ acetic acid and $0.1 \mathrm{M}$ hydrochloric acid. Table 3 presents the results obtained for the physico-chemical characteristics of the hydrogels studied. There are higher values for calf collagen in comparison to the one obtained from fish, for ash, total nitrogen and mineral content. Comparable values for protein content and collagen content were obtained for the hydrogel made from bovine and Gray Mulletskin using the $0.5 \mathrm{M}$ acetic acid extraction process. The results obtained for the bovine and Gray Mllet collagen obtained using the $0.5 \mathrm{M}$ acetic acid extraction process are in accord to data literature [32, 42]. The $\mathrm{pH}$ range is 2.5-3.5 (table 3) and is in accordance to data literature [32].

The content of collagen calculated on the basis of the percentage of hydroxyproline with equation (1) is comparable for calf collagen (92.2\%) and fish collagen extracted with $0.5 \mathrm{M}$ acetic acid (90.1\%). Smaller values (82.3\%) were obtained for fish collagen extracted with 0.1 $\mathrm{M} \mathrm{HCl}$. The highest moisture content is the hydrogel obtained from the collagen fish extracted with $0.5 \mathrm{M}$ acetic acid (15.5\%) compared to calf collagen (13.5\%). The appearance is different: translucent gelatinous for calf collagen, white/ opaque gelatinous for fish collagen.

\section{Analysis by FT-IR spectroscopy}

The IR spectrum of the collagen hydrolyzate from both the calf skin and Gray Mullet skin has absorption bands located in the amide band, as can be seen in the FTIR spectrums obtained and presented in figure 1 ( $a$ and $b$ ). The main absorption bands of amides A, I, II and III were between $3326-1643$ and $1527-1238 \mathrm{~cm}^{-1}$, respectively. Amides I, II and III (1650 and $1200 \mathrm{~cm}^{-1}$, respectively) are

Table 3

PHYSICO-CHEMICAL CHARACTERISTICS OF COLLAGEN HYDROGELS

\begin{tabular}{|l|l|l|l|}
\hline $\begin{array}{l}\text { Characteristics of } \\
\text { hydrogels }\end{array}$ & Calf collagen & $\begin{array}{l}\text { Fish collagen extracted } \\
\text { with } \\
0.5 \mathrm{M} \text { acetic acid }\end{array}$ & $\begin{array}{l}\text { Fish collagen } \\
\text { extracted with 0.1 } \\
\text { M HCl }\end{array}$ \\
\hline Appearance & translucent gelatinous & white gelatinous & white opaque \\
\hline Color & White-yellow & White-yellow & White-yellow \\
\hline Humidity [\%] & $13.5 \pm 0.1$ & $15.5 \pm 0.1$ & $15.0 \pm 0.2$ \\
\hline Dry matter [\%] & $1.75 \pm 0.02$ & $1.55 \pm 0.04$ & $1.2 \pm 0.03$ \\
\hline Ash 600-800 ${ }^{\circ} \mathrm{C}[\%]$ & $1.5 \pm 01$ & $0.7 \pm 0.2$ & $0.8 \pm 0.2$ \\
\hline Total nitrogen mg (Khieldal) [\%] & $16.5 \pm 0.1$ & $10.9 \pm 0.2$ & $8.8 \pm 0.3$ \\
\hline Proteic substance [\%] & $90.5 \pm 0.2$ & $86.5 \pm 0.1$ & $78.5 \pm 0.3$ \\
\hline pH & $2.9 \pm 0.1$ & $3.5 \pm 0.3$ & $2.5 \pm 0.2$ \\
\hline Collagen content [\%] & $92.2 \pm 0.1$ & $90.1 \pm 0.2$ & $82.3 \pm 0.4$ \\
\hline
\end{tabular}

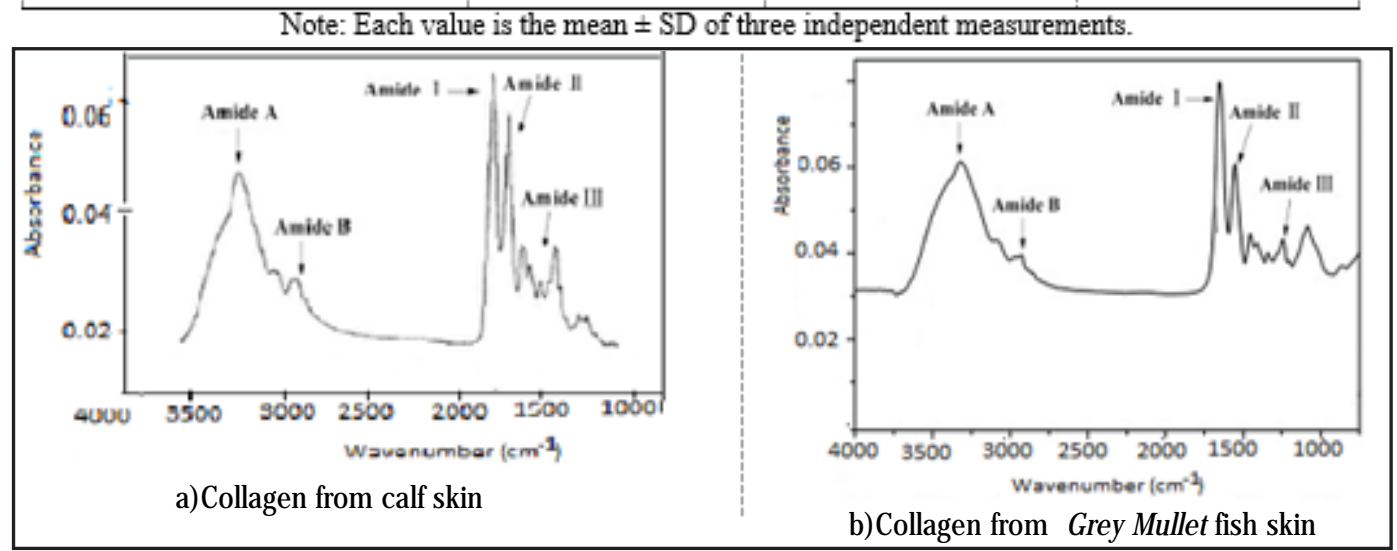

Fig. 1. FTIR spectra of collagen from the skin of Grey Mullet (a) anf calf (b)extracted. 
found, which is in line with data literature [43]. An absorption ratio of approximately 1 , between the amide III and the 1450-1454 $\mathrm{cm}^{-1}$ band, indicates that triple helical structure is intact in accordance with data literature [44]. The triple-helical structure of collagen extracted by the acidic fish skin method was confirmed from the absorption ratio between 1238 (amide III) and $1527 \mathrm{~cm}^{-1}$, which is approximately 1, in accordance with literature data [45].

The same method has been used frequently in many scientific reports [43] which indicated that FTIR was a simple and practical method for assessing the triple-helical structure of collagen.

\section{Analysis by UV-DC spectroscopy}

UV circular dichroism (UV-DC) measures the differential absorption of circularly polarized light. Amide links of proteins found in highly ordered regions - helixes $\alpha$ and folded structures $\alpha$ - have specific optical activity due to orientation (fig.2). To avoid saturation of the detector, the sample concentration should be small enough $(<0.125$ $\left.\mathrm{mg} \cdot \mathrm{mL}^{-1}\right)$. From figure $2(a$ and $b$ ) the following can be highlighted: close wavelength values were obtained ( 198.5 $\mathrm{nm}$ for fish collagen and $198 \mathrm{~nm}$ for bovine collagen); the values obtained for the maximum wavelengths were also close ( $221.5 \mathrm{~nm}$ for fish collagen and $222 \mathrm{~nm}$ for bovine collagen); the values for the zero ellipticity point for fish collagen ( $215.5 \mathrm{~nm})$ and for the zero elipticity point for calf collagen ( $214 \mathrm{~nm}$ ) are comparable; similar values were obtained for Rpn parameter value 0.10 for fish collagen and Rpn value 0.12 for bovine collagen.

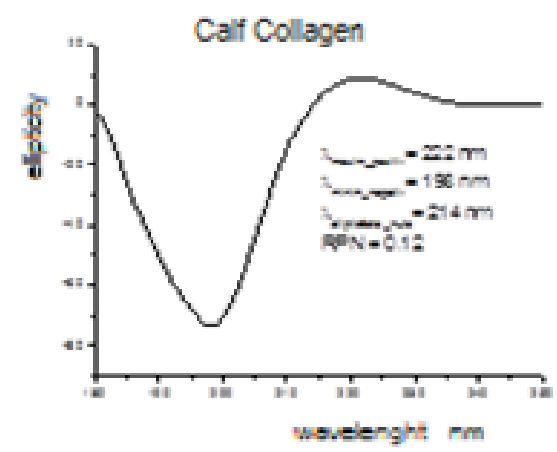

a)Collagen from calf skin

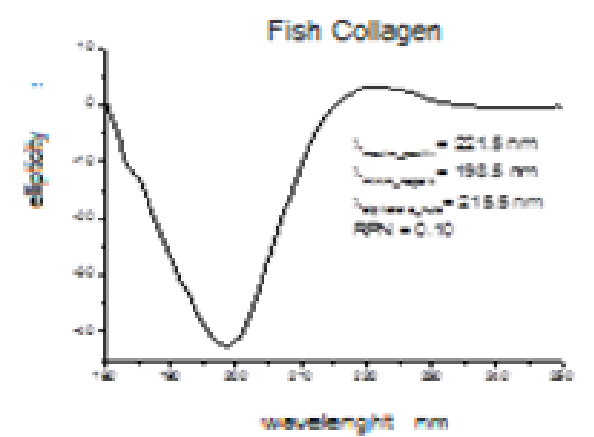

b)Collagen from Grey Mullet fish skin

Fig. 2. Comparative circular dichroism spectra of fish and calf collagen at $25^{\circ} \mathrm{C}$

\section{Rheological behavior}

Improvement of mechanical properties can be achieved through crosslinking. The disadvantage of chemical crosslinking is reducing the biocompatibility of hydrogels and these become cytotoxic [46]. Among the beneficial effects of reticulation, it can be mentioned: improvement of mechanical properties, increase of proteolytic resistance and solvents [48], reduction of antigenicity [49]. In the case of tannic acid crosslinking, only $\mathrm{pH}$ acidic hydrogels were prepared because AT rapidly and relatively tightly binds to collagen only under acidic conditions, at $p H$ values ranging from 2 to 4 . Above the $p H$ value of 7 , its binding is slow and incomparably weaker. The researched collagen hydrogels are presented in table 1. Rheological parameters and obtaining the reograms and flow curves were made with the set of equations ( 2$) \div(5)$ of table 2 .

\section{Characterization by dynamic rheological behavior for calf collagen}

Rheological measurements in a stationary system affect the structure of the dispersed systems, due to the shear forces to which they are subjected, while the ones in the dynamic regime do not affect the systems so that the rheological parameters determined maintain their actual values. Apparent viscosities of different concentrations of calf collagen were determined in successive dilutions of $1,0.5,0.25 \%$ shown in figure 3 . It can be concluded that the apparent viscosity increases with increasing collagen concentration. The $1 \%$ collagen solution exhibits a rheological profile characteristic of elastic behavior with $\mathrm{G}^{\prime}$ (storage modulus) much greater than $\mathrm{G}^{\prime \prime}$ (the loss of viscosity) and almost independent of frequency. For crosslinked collagen, the mixture becomes characteristic of a viscoelastic fluid, butfor high concentrations of collagen, (fig.3.B).

This can be explained by a concentration of tannic acid, which is sufficient to ensure a good combination of tannic acid in chains, leading to a transient network.
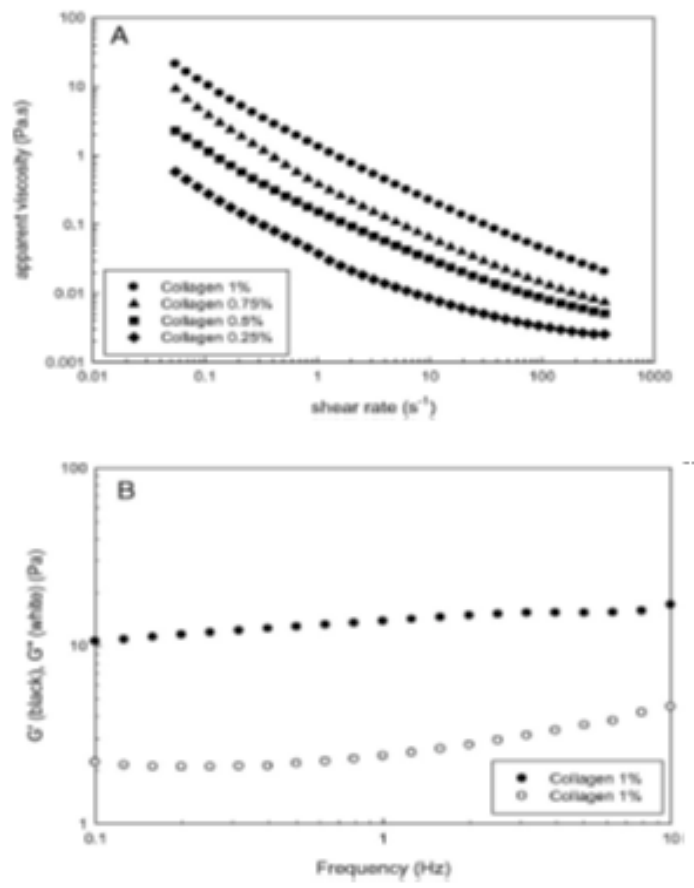

Fig. 3 The rheological behavior of calf collagen at different concentrations in pure water solutions - flow and dynamic measurement for $\mathrm{A}$ and $\mathrm{B}$

Characterization by dynamic rheology behavior for fish collagen

The dependence of storage and loss modulus on the angular frequency for sample 3 , collagen over nonreticulated at $25^{\circ} \mathrm{C}$, is shown in figure 4.a.

The sample has a gel point at approx. $1 \mathrm{rad} / \mathrm{s}$, below this value the sample is predominantly viscous, and above this value predominantly gel. Dependence of storage and loss modulus on angular frequency for sample 4, collagen fish crosslinked at $25^{\circ} \mathrm{C}$, is shown in figure 4.b. The sample is at the gel point in the range of about $3-10 \mathrm{rad} / \mathrm{s}$, below $3 \mathrm{rad} / \mathrm{s}$, the sample being predominantly viscous, and 


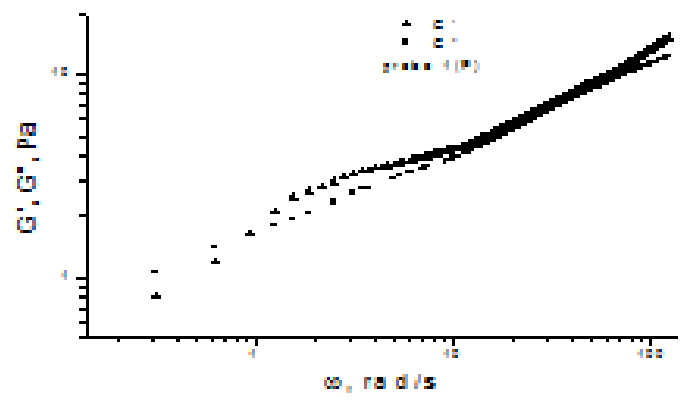

a) Fish collagen non-reticulates (sample 3)

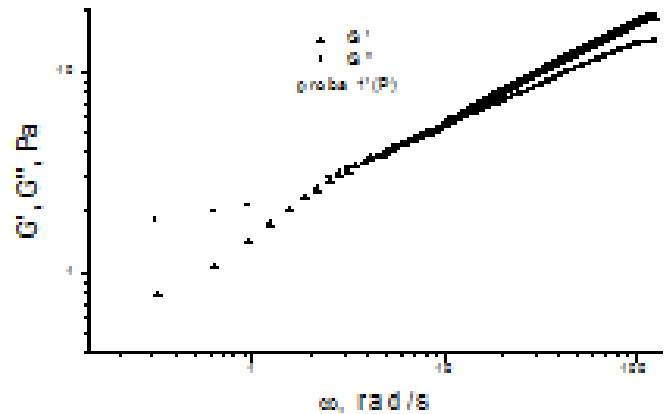

b) Fish collagen reticulated with tanic acid (sample 4)

Fig. 4. Storage and loss modules for fish collagen

over $10 \mathrm{rad} / \mathrm{s}$ having predominantly gel nature. Figure 5.a shows the dependence of the storage and loss modules on the angular frequency for the collagen sample of the calf at $25^{\circ} \mathrm{C}$. The sample has a gel point at approx. $3.8 \mathrm{rad}$ $/ \mathrm{s}$, is predominantly viscous under the gel point and predominantly gel over the gelification point. Figure $5 . b$ shows the dependence of storage and loss-of-angles for sample 1 for fish at $25^{\circ} \mathrm{C}$. The sample has a predominantly visc ous character for $\omega<65 \mathrm{rad} / \mathrm{s}$ and is at the gel point for $\omega>65 \mathrm{rad} / \mathrm{s}$.

\section{Determination of total antioxidant activity by} chemiluminescence $(A C L)$

From the examination of curves obtained using the Photochem instrument with ACL kitt (Analytic Jena AG) which are shown in figure 6 shows that all samples with collagen hydrolysates show antioxidant activity reported as trolox units equivalents ( $\mathrm{mmol} /$ sample volume). Analyzing the calf collagen and collagen fish hydrogels mixed with water, $40 \%$ ethyl alcohol and $50 \%$ ethyl alcohol we concluded that in all mixtures made of collagen fish

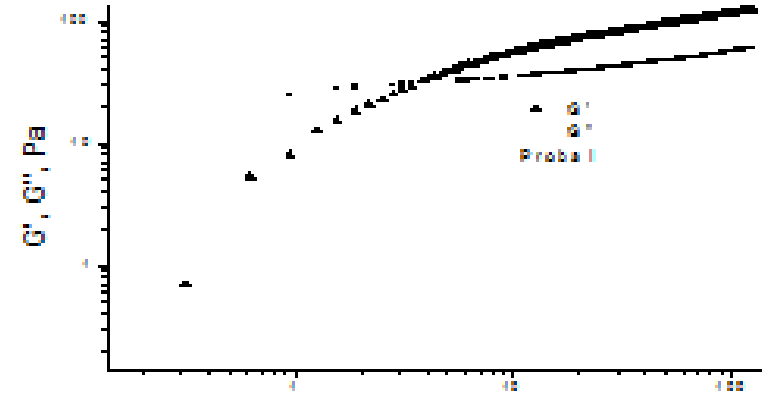

$\omega$, ra d/s

a) Calf collagen

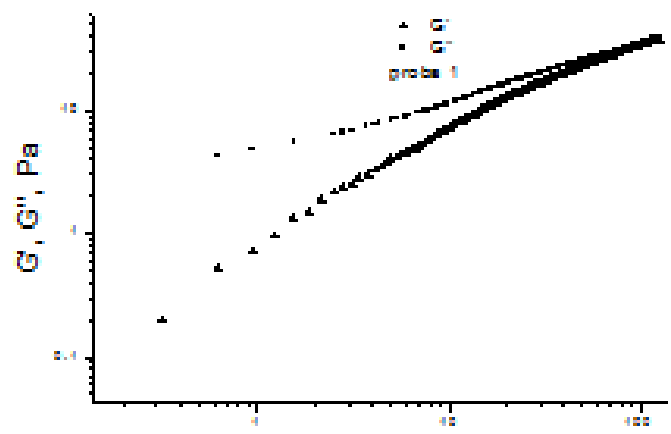

Q. $\mathrm{rad} / \mathrm{s}$

b) Grey Mullet fish collagen

Fig. 5. Storage and loss modules for collagen hydrogels

shows values higher than total collagen for total antioxidant capacity expressed as trolox units equivalents (mmol/ sample volume), as shown in figure 7.

For example, in the case of mixtures with water, the calf collagen has an ACL of 0.368 nmole trolox /sample volume, and the fish collagen has an ACL of $0.456 \mathrm{nmol}$ trolox/sample volume.

For blends with $40 \%$ ethyl alcohol, the calf collagen records an $A C L$ of $0.280 \mathrm{nmol}$ trolox/sample volume, and the fish collagen records an ACL of $0.323 \mathrm{nmol}$ trolox/ sample volume, and for blends with $50 \%$ ethyl alcohol, the calf collagen records an ACL of $0.097 \mathrm{nmol}$ trolox / sample volume and fish collagen records $A C L$ of $0.205 \mathrm{nmol}$ trolox/ sample volume. The collagen hydrolyzate in aqueous solution has antioxidant activity in the analyzed samples. ACL (total antioxidant capacity) decreases with increasing sample dilution. Figure 7 shows that the aqueous collagen hydrolyzates exhibit the highest values for ACL (Fish collagen $0.456 \mathrm{nmol}$ trolox/sample volume and calf collagen with $0.368 \mathrm{nmol}$ trolox units equivalents/sample volume).

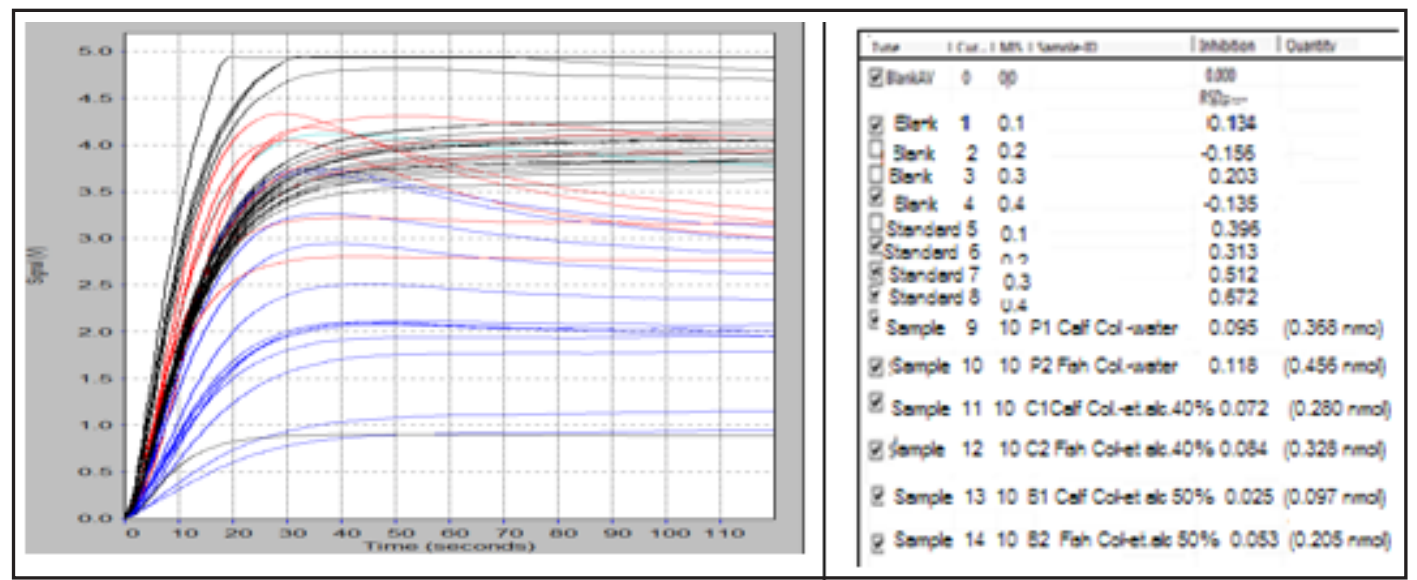

Fig. 6. Antioxidant capacity (nmoles trolox /mg fresh weight) for calf collagen and fish collagen measured using Photochem equipment 


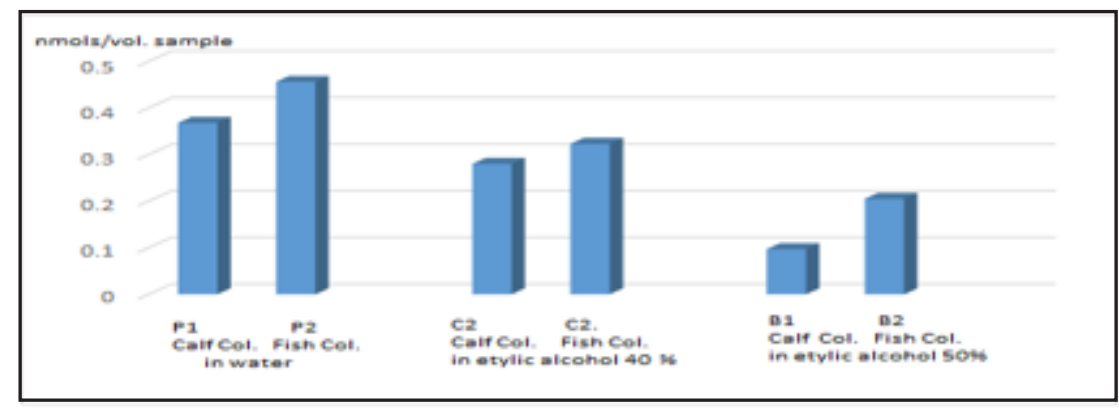

Fig. 7. Results for $A C L$ for mixtures of bovine collagen and fish collagen

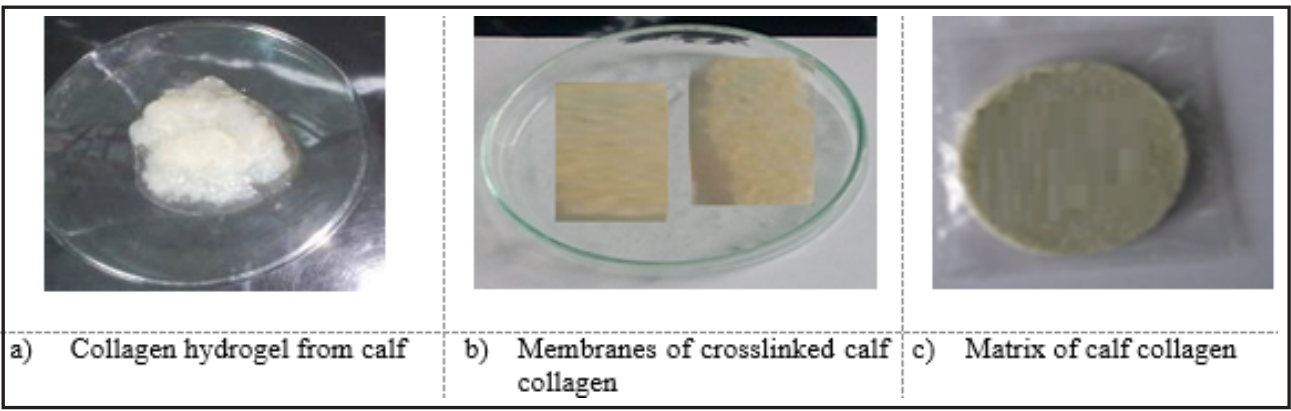

Fig. 8. Biomaterials from caf collagen

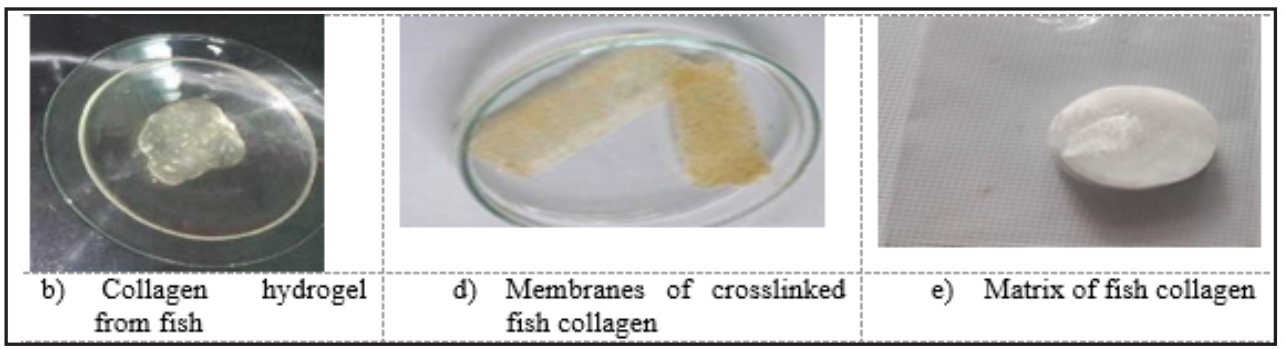

Fig.9. Biomaterials from Grey Mulett fish collagen

Table 4

ANTIBACTERIAL ACTIVITY OF COLLAGEN HYDROGELS AGAINST BACTERIAL SPECIES TESTED BY DISC DIFFUSION ASSAY

\begin{tabular}{|l|c|c|}
\hline \multicolumn{1}{|c|}{ Bacterial Strains } & \multicolumn{2}{|c|}{ Inhibition Zone (mm) } \\
\hline Calf collagen hydrogel 1\% & Staphlococcus aureus & Escherichia coli \\
\hline Calf collagen hydrogel $2.5 \%$ & $4.5 \pm 0.3$ & $4.0 \pm 0.2$ \\
\hline Fish collagen hydrogel $1 \%$ & $6.0 \pm 0.4$ & $5.0 \pm 0.1$ \\
\hline Fish collagen hydrogel $2.5 \%$ & $5.0 \pm 0.5$ & $4.8 \pm 0.23$ \\
\hline
\end{tabular}

Note: Each value is the mean \pm SD of three independent measurements.

\section{Collagen biomaterials}

Collagen hydrogels obtained from calf collagen (fig. 8a) are different in appearance from those obtained from Gray Mullet fish collagen (fig. 9a).

To obtain the collagen membranes, the crosslinked hydrogels with tannic acid were poured into Petri dishes, after a prior agitation to remove the air, the free-drying method was applied. Collagen calf membranes (fig. 8b) can be compared to those in fish collagen (fig. 9.b).

To obtain the collagen membranes, the crosslinked hydrogels with tannic acid were poured into Petri dishes, after a prior agitation to remove the air, the free-drying method was applied. Collagen calf membranes (fig. 8b) can be compared to those in fish collagen (fig. 9b).

\section{Antimicrobian activity}

The in vitro antibacterial potential of collagen hyrogels against both gram-positive and gram-negative bacteria is summarized in table 4.

Calf collagen presents zones of inhibition between 4.5$6 \mathrm{~mm}$ of diameter, for Staphylococcus aureus, higher than Escherichia coli with zones of inhibition between 4.0-5.0 $\mathrm{mm}$ of diameter. Gray Mulletfish collagen also has inhibition zones between 5.0-6.5 mm diameter for Staphylococcus aureus, larger than Escherichia coli with zones of inhibition between 4.8-6.0 mm in diameter. Fish collagen exhibits better antimicrobial activity compared to calf collagen.

\section{Conclusions}

The paper presents physico-chemical characteristics of collagen hydrogels derived from bovine skin compared to collagen extracted from Gray Mullet skin from the Black Sea. Collagen hydrogels from marine fish were obtained by two different acid extraction processes: $0.5 \mathrm{M}$ acetic acid and $0.1 \mathrm{M}$ hydrochloric acid. From the comparison of physico-chemical characteristics we can draw the following conclusions:

Fish collagen extracted from Gray Mullet fish using the acetic acid $0.5 \mathrm{M}$ method shows superior values to that obtained with the $0.1 \mathrm{M} \mathrm{HCl}$ acid process for all the characteristics analysed and is comparable to the results obtained for calf collagen. The highest collagen content value obtained is from calf collagen (92.2\%) comparable to that from fish collagen (90.1\%) obtained using the $0.5 \mathrm{M}$ acetic acid process.

From analysis by FT-IR spectroscopy, the triple helical collagen structure for both fish and calf collagen was confirmed in accordance with literature data [ $43 \div 45]$.

-From analysis by UV-DC spectroscopy, the results show that during the extraction the triple helix structure of the collagen wasn't affected and both the collagen hydrogels obtained from fish and calf can be utilized for biomaterials.

From the rheological behaviour we concluded that all hydrogels are found to have pseudoplastic behaviour, but viscosities are much higher at a given concentration for 
those using $0.5 \mathrm{M}$ acetic acid extracts from marine fish, becoming predominantly elastic. The collagen rheograms in fish are similar to those of the calf, the curves being descending and depending on the shear forces.

From the ACL study (total antioxidant capacity) presented by the hydrogels from calf and marine fish in aqueous and alcoholic solutions it is found thatall samples showed antioxidant activity. It is also found that collagen hydrolyzate exhibits higher antioxidant activity in $40 \%$ ethyl alcohol solutions over the same collagen concentrations in $50 \%$ ethyl alcohol solutions.

-Study on those strains showed a more intense activity on Staphylococcus aureus than on Escherichia coli, which proves the effectiveness of these biomaterials for the intended destinations, namely skin infections.

From the collagen hydrolyzers, biomaterials with multiple topical applications can be made in the form of hydrogels, membranes and collagen matrices, both from calf collagen and fish collagen. Biomaterials made from GrayMulletfish in the Black Sea have notable advantages due to the antioxidant and antimicrobial properties they possess.

\section{References}

1. MOES, A.J., J .Pharm. Belg., 48 (4), 1993, p. 252-260.

2. SANTOS, M.H., SILVA, R.M., DUMON, V.C., NEVES, J.S., MANSUR, H.S., HENEINE, L.G.D., Materials Science and Engineering, 33 (2), 2013, p. 790-800

3. SILVA, T.F., AND PENNA, A.L.B., Revista do Instituto Adolfo Lutz, 71 (3), 2012, p. 530-539.

4. DAMODARAN, S., PARKIN, K., FENNEMA, O.R., Química de alimentos de fennema, 4a Ed. Sao Paulo, Armed, 2010, p .726-730.

5.MILLER, EJ., REDDI, A. H.(Ed.), PIEZ, R.A., Extracellular Matrix Biochemistry, Eds. Elsevier, New York. 1984, p. 41-81.

6.SILVIPRIYA, K.S., KRISHNA KUMAR, K., BHA, A.R., DINESH KUMAR, B., ANISH J OHN, J., J. Appl. Pharm. Sci., 5 (03), 2015, p. 123- 127.

7.NELSON, D.L., COX, M.M., Lehninger, Principles of Biochemistry, W. H. Freeman \&Co, 4 a Ed. New York, 2005, p.1119.

8.SZPAK, P., J.Archaeol. Sci., 38(12), 2011, p. 3358-3372.

9.FRIESS, W., Eur. J. Phare. Biopharm, 45, 1998, p. 113-136.

10.KRISHNAN, S., PERUMAL, P., Int. J.Pharm.Pharmacol. Sci., 5 (3), 2013, p. 698-701.

11.SUGIURA, H., YUNOKI, S., KONDO, E., IKOMA, T., TANAKA, J., YASUDA, K., J. Biomater. Sci. Polym., 20, 2009, p. 1353-1368,

12. SONG, E., YEON KIM, S., CHUN, T., BYUN, H.J., LEE, Y. M., Biomaterials 27, 2006, p. 2951-2595.

13.STRAWIC, E, NIMNI, M.E., Biochemistry, 10 (21), 1971, p. 39053911.

14.BOGZA, G.E., CHELARU, L., BITERE, E., POROCH, V., SULEA, D., COSTULEANU, M., Rev.Chim.(Bucharest), 67, no. 11, 2016, p. 22952298.

15. GHICA, M.V., ALBU, M.G., DINU-PIRVU, C., MOISESCU, S., Rev. Chim. (Bucharest), 63, no. 9, 2012, p. 929-935.

16. BECHIR, A., SIRBU, R., PACURAR, M., PODARIU, A.C., MONEA, M., BECHIR, E.S., GHERGIC, D.L., Rev. Chim.(Bucharest), 65, no. 3, 2014, p. 362-368.

17.YATES, C.C., WHALEY, D., BABU, R., ZHANG, J., KRISHNA, P., BECKMAN, E., PASCULLE, A.W., WELLS, A., Biomaterials, 28, 2007, p. 3977-3986.

18.SCULLY, C., PORTER, S.R., Oral Medicine for the Dental Health Team, Churchill Livingstone, Edinburgh, 2003, p. 35-69.
19.NELSON, G., ALTMAN, A.D., NICK, A., MEYER, L.A., RAMIREZ, P.T., ACHTARI, C., ANTROBUS, J, HUANG, J., SCOTT, M., WIJK, L., ACHESON, N., LJUNGQVIST, O., DOWDY, S.C., Gynecol. Oncol., 140 (2), 2016, p. 323-332.

20.ISHIHARA, M., NAKANISHI, K., ONO, K., SATO, M., KIKUCHI, M., SAITO, Y., YURA, H., MATSUI, T., HATTORI, H., UENOYAMA, M., KURITA, A., Biomaterials, 23, 2002, p. 833-840.

21.ZHANG, F.F., GAN, L.L.H, ZHOU, C., Bioorganic \& Medicinal Chemistry Letters, 20 (6), 2010, p. 1881-1884.

22.KOIDE, M., OSAKI, K., KONISHI, J., OYAMADA, K., KATAKURA, T, TAKAHASHI, A., YOSHIZATO, K., J. Biomed Mater. Res. 27 (1), 1993, p. $79-87$.

23.LI, Z.R., WANG, B., CHI, C.F., ZHANG, Q.H., GONG, Y.D., TANG, J.J ., LUO, H.Y., DING, G.F., Food Hydrocolloids, 31 (1), 2013, p. 103-113.

24. ALBU, M.G., GHICA, M.V., GIURGINCA, M., TRANDAFIR, V., POPA, L., COTRUT, C., Rev. Chim.(Bucharest), 60 , no. 7, 2009, p. 666-672. 25.GOMEZ-GUILLEN, M.C., GIMENEZ, B., LOPEZ-CABALLERO, M.E., MONTERO, M.P., Food Hydrocolloids, 25, 2011, p. 1813-1827.

26.GAIDAU, C., PETICA, A., MICUTZ, M., DANCIU, M., VLADKOVA, T., Cent. Eur. J. Chem. 11 (6), 2013, p. 901-911.

27.PARENTEAU-BAREIL, R., GAUVIN, R., BERTHOD, F., Materials. 3 (3), 2010, p. 1863-1887.

28.AHUJA, T., DHAKRAY, V., MITTAL, M., KHANNA, P., YADAV, B., JAIN, M., Internet J. Microbiol., 10, 2012, p. 1-10.

29.ADDAD, S., JEAN-YVES, E., FAYE, C., SYLVIE RICARD-BLUM, S., LETHIA, C., Mar. Drugs, 9 (6), 2011, p. 967-983.

30.CHERIM, M., RASIT, E.Y., J. Sci. Arts, 4 (45), 2018, p. 1015-1024.

31.WANG, L., LIANG, Q., CHEN, T., WANG, Z., XU, J., MA H., Food hydrocolloids, 38, 2014, p.104-109.

32.FICAI, A., ANDRONESCU, E., GHITULICA, C., VOICU, G., TRANDAFIR, V., MANZU, D., FICAI, M., PALL, S., Mat. Plast., 46 , no. 1, 2009, p. 1115.

33.CHERIM, M., STANCIU, G., RASIT, E.Y., CADAR, E., J. Sci. Arts , 4 (41), 2017, p. 795-802.

34. *** Romanian Pharmacopoeia X-th Edition, S., 2006, Medical Ed., Bucharest, 2006.

35.*** European Pharmacopeea, Council of Europe, Strasbourg Ed. 8th, 2014.

36.MACOVESCU, G., CHELARU, C., ALBU KAYA, M.G., Leather and Shoes J ournal, 16 (2), 2016, p. 147-162.

37.*** ISO 3496, Meat and meat products. Determination of hydroxyproline content, 1997.

38.YANG, H., YANG, S., KONG, J., DONG, A., YU, S., Nat. Protoc, 10, 2015, p. 382-396.

39.POPOV, I., LEWIN, G., Methods of Enzymology, 300, Oxidants and Antioxidants. Part B (Ed. L. Packer), Academic Press, 1999, p. 437-456. 40.BAUER, A.W., KIRBY, W.M., SHERRIS, J.C., TURCK, M., Am. J. Clin. Pathol. 45 (4), 1966, p. 493-496.

41.TAYEBJ EE, M.H., MACFADYEN, R.J., LIP, G.Y., J. Hypertens. 21 (12), 2003, p. 2211-2018.

42.MENDRYCKA, M., KOWALSKA, M., MYJAK, W., Rev. Mat. Plast, 53 (1), 2016, p. 113-118.

43.MUYONGA, J.H., COLE, C.G.B., DUODU, K.G., Food Hydrocolloid, 18 (4), 2004, p. 581-592.

44.PLEPIS, A.M.D.G., GOISSIS, G., DAS-GUPTA, D.K., Polym. Eng. Sci. 36 (24), 1996, p. 2932-2938.

45.AHMAD, M., BENJ AKUL, S., Food Chem., 120 (3), 2010, p. 817-824. 46.CHARULATHA, V., RAJARAM, A., Biomaterials, 24 (5), 2003, p. 759767.

48.FRIESS, W., Europ. J. Pharma. Biopharma., 45, 1998, p. 113 - 136. 49.J ANCAR, J., HYNSTOVA, K., PAVELKA, V., Comp. Sci. Tech., 69 (34), 2009 , p. 457 - 462.

Manuscript received: 3.12 .2018 